tion, numerous contemporary examples of water barriers also exist that have effects at all scales on the distribution and character of marine sediments. Because these are also the precursors of most source and reservoir rocks, an understanding of their effects is of basic importance to petroleum geolagists.

On a relatively small scale, circulation patterns in Florida Bay, at the southern tip of the Florida peninsula, are slow tidally controlled gyres which create a flow that probably prohibits sediment transport into the central portions of the individual "lakes" of this broad shallow embayment. Thus the sediment accumulation occurs around the periphery of the individual segments and these lines of sedimentation in turn appear to coincide with the locus of points of small or zero tidal amplitude. Current transport of these materials also takes place and thus they ultimately come to rest in the deep water of the Florida Straits.

In large coastal bays on the Pacific coast, water circulation also plays a strong part in the distribution of sediment types. Sebastián Viscaino Bay is an open, broad, north-facing embayment that also forms the southern extremity of the continental borderland off California and Baja California. Within this huge embayment the California Current turns back on itself and forms a large gyre. The patterns of texture, bioclastics, and organic content are strongly controlled by this circulation pattern and, in fact, parallel the contours of flow.

Work by K. S. Rodolfo at U.S.C. shows that the shift in the monsoon and the period of strong river flow combine in the Andaman Sea to restrict Irrawaddy sedimentation to the confines of the sea even though no physiographic barrier is present to hinder flow to the adjacent Bay of Bengal. Thus, the sedimentation in the two areas is from two different sources producing lenses of sedimentation of geosynclinal scale side by side from different sources. The development of the entire Andaman margin is effectively controlled by these circumstances.

Off the southern Atlantic coast of the United States, the Gulf Stream forms an effective boundary to the detrital terrigenous sediments of the upper sheif and the bioclastic sediments of the outer shelf and Blake Plateau. The combination of broad shelf and strong regional current also influences the form of the coast and apparently also prevents the active formation of submarine canyons.

\section{HAROLD MASURSKY}

Lunar Stratigraphy and Sedimentation

(Abstract to be published in November issue of Bulletin.)

JAMES R. McNITT, California Div. Mines and Geology, San Francisco, Calif.

Status of Geothermal Resources Development

The total installed capacity of geothermal generating plants in the world today is approximately 620 $\mathrm{MW}$, distributed among the following five countries: Italy, 340; New Zealand, 190; USA, 50; USSR, 30; and Japan, 10. Although exceedingly small in comparison with the world's total generating capacity from conventional sources, the rapid growth of this new industry is reflected by the fact that more than half of this present geothermal capacity has been installed during the last 10 years. The success of these installations is stimulating worldwide interest in geothermal energy, and exploration projects are now underway in Mexico, El Salvador, Chile, Turkey, Kenya, China (Taiwan), and the Philippines.

The principal incentives for development of geothermal power are: (a) the lack of more conventional sources in the market area, and (b) the competitive economic position of geothermal power even in those areas where other sources are available. Geothermal sources generate low-cost power even at capacities under $100 \mathrm{MW}$, making them particularly advantageous in market areas where power demands are still low. Low steam pressures make it necessary to use small generating units, i.e., on the order of $25 \mathrm{MW}$, but total capacities of several hundred megawatts can be expected from a single steam field.

All the thermal areas now under investigation share a common regional geologic setting: the areas are $]_{0}$ cated in orogenic zones, where late Tertiary or (ua ternary volcanism has taken place. The thermal areas, however, are not necessarily in close proximity to volcanic centers. Tectonically the regions are characterized by vertical movements, both uplift and subsidence, which have taken place on normal faults. Fault blocks, tilted consistently in one direction, appear to be more common than horst and graben structures.

Variations in local structure, stratigraphy, and hydrology result in considerable differences in the geologic characteristics of individual steam fields. Fault zones, permeable strata, or a combination of both, can form thermal fluid reservoirs. Although it is now generally agreed that the heat sources are shallow intrusive bodies and the thermal fluid is at least $95 \%$ meteoric in origin, there are still many fundamental problems as yet only partly answered. How is the heat transfer actually accomplished? Do phase changes occur in the thermal fluid under natural conditions or only when the system is under exploitation? What are the roles of convection currents and caprocks in forming an economically exploitable deposit? What factors determine the life expectancy of the field?

Geothermal exploration methods have not advanced far beyond the stage of merely drilling on hot springs, except in Italy where geothermal gradient surveys have been applied successfully. Recent results from deep resistivity surveys, however, indicate that this method holds considerable promise. Much progress has been made in understanding the chemistry of thermal systems and in the near future this knowledge should form the basis of effective exploration methods.

Although the successful development of geothermal resources offers a great challenge to exploration geologists and engineers, it offers no less a challenge to power legislators, planners, and administrators. Because natural steam must be utilized when and where it is produced, successful development requires the closest cooperation between the exploration groups and the power marketing and distribution sector. Rapid development of geothermal power cannot be expected until these two groups, and the legislators who control their activities, arrive at a mutual understanding of each others' problems.

FRANCIS G. STEHLI, Western Reserve Univ,, Cleveland, Ohio

Paleoccolocical Reconstruction of Depositionat. Environments - Some Techniques of Possible EXPloRation IntEREST

Organisms are extremely sensitive to many parameters of the physical environment and their fossil re mains may thus be used in the interpretation of an- 
cient environments. Effective use of paleoecology depends first on determining what environmental parameters are of interest, second, on developing a model based on recent examples which can be tested on the fossil record, and third, testing the model on the fossil record. Following this procedure several methods for determining the depth of water in which deposition took place are considered. Though further testing is required, each of these procedures appears to offer promise for environmental reconstruction and for petroleum exploration. Additional techniques which consider the distribution of ocean currents across the continental shelves are also examined and appear to offer possibilities for the interpretation of ancient submarine topography which may be of significance in exploration.

Climatic conditions strongly affect the distribution of certain stratigraphic traps, particularly such carbonate traps as reefs. Exploration for these traps is fruitless if climatic conditions at a particular time and place were such as to preclude their development. Determination of past climatic zones is, however, difficult if not impossible until the positions of the major continental masses in the past can be determined. Paleoecology with its ability to reconstruct depositional environment is in a strong position to examine both the question of continental drift and the question of polar wandering. A model which permits such an examination is developed and tested on the fossil record of the Permian. The test suggests that neither continental drift across latitude, nor polar wandering is likely and that both the rotational poles and the latitudinal positions of continents probably have remained unchanged at least since the Permian. If this is true then the limits of tropical-subtropical conditions have varied widely through time controlling, as they varied, the area of the globe suitable for reef development and, in fact, for extensive carbonate development.

A modification of the model used to test the hypotheses of continental drift and polar wandering shows promise for reconstructing the pattern of surface oceanic currents. These currents are closely related to reef development which extends farther both toward the north and south on the east side of the continents than on the west because of these currents. The same technique suggests a possible means of learning more of the fundamental courses of glaciation if applied to glacial and interglacial patterns of oceanic circulation.

\section{PROPOSED AMENDMENT TO BYLAWS: REVISED ETHICS PROCEDURE}

The Fxecutive Committee has approved the revision of the ethics procedure provided in the Association bylaws. The revision, if approved by the annual business meeting in Oklahoma City in April 1968, will bring the Association's procedures into conformity with modern practices by other professional organizations.

The proposed article below will replace Sections 5, 6,7 , and 8 of Article II of the bylaws and subsequent articles will be renumbered.

\section{ARTICLE III}

SECTION 1. The commission by any member of any classification of this Association of any act contrary to the provisions of the Code of Ethics as promulgated by this Association shall be grounds for disciplinary action. The fact that certain acts of unprofessional con- duct may at times have remained unchallenged shall not impair the jurisdiction of the officials of this Association, nor excuse a wrongdoer.

SECTION 2. Charges of misconduct in violation of the Code of Ethics of the Constitution of this Association shall be in writing and filed with the Executive Director at the headquarters of this Association, with a full statement of the evidence upon which the charges are based. Such writing may be signed by either a member of this Association or a member of the public

SECT ION 3. Discipline by this Association shall be : (a) expulsion from membership; (b) suspension for a stated period of time; or (c) reprimand. Discipline for misconduct shall be according to the evidence, and the disciplining authority may consider prior misconduct of the accused resulting in discipline. Discipline shall always be considered not as an imposition of punishment, but primarily for the protection of the public

(a) Upon the filing of the charges as provided in Section 2 above, the same shall be referred by the President to the Grievance Committee, which committce shall meet at Association headquarters and examine such charges to ascertain if they merit further consideration. If, in the judgment of such Grievance Committee, the facts warrant, such committee shall prepare and file with the Executive Director formal charges against the accused for transmittal to the Executive Committee.

(b) The Executive Committee shall thereafter and with dispatch fix a date for hearing at Association headquarters thereon and shall give to the accused notice in writing of such charges, mailed to him by registered mail at his last known post office address, not less than thirty (30) days before said trial date, accompanied by a copy of the charges and a copy of this Article III.

(c) The Executive Committee shall be the trial authority to hear and determine said charges. On the day fixed for the hearing the accused person may appear in person, cross-examine any witnesses, submit oral or written statements, and witnesses in his own behalf. He may also, at his option, submit by registered mail to the Executive Committee, to be received at the Association headquarters not less than ten (10) days prior to the date of the hearing, a written statement of his defense, together with any other written documents he may desire to submit.

SECTION 4. At the conclusion of the hearing the Executive Committee shall vote as follows: (a) expel such member; (b) suspend such member for a definite period of time; (c) reprimand such member; or (d) dismiss such charges. A member may be permitted to resign at any stage of grievance proceedings; however, a permanent personal file shall be kept on such member which shall include a complete record of all grievance procedures up to the date of resignation of such member. Resignation shall not necessarily suspend or discontinue pending grievance matters against a member. Further proceedings shall be at the discretion of the Executive Committee.

SECTION 5. The decision of the Executive Committee in all grievance matters shall be final; and, annually, each member paying his dues shall be considered as reaffirming the condition agreed to in his application for membership in this Association.

SECTION 6. All grievance procedures shall be secret records, subject to be opened only at the discretion of the Executive Committee.

SECTION 7. Neither the members of the Executive Committee, any Grievance Committee, the officers, staff 